\title{
Problems and Countermeasures of English Translation on Tea Export Packaging
}

\author{
Xie Yutong \\ Department of Foreign Languages, Guangdong Vocational Institute of Public Administration, \\ Guangzhou, China 510800
}

Keywords: traditional arts and crafts; modern art design education; application

Abstract: With the rapid development of Chinese economy, the export volume of Chinese tea is gradually increasing. And the tea is deeply loved by foreign people. At the same time, tea packaging is the symbol of our national brand. It also shows our culture and comprehensive national strength. However, there are many English translation problems of tea export packaging in some kinds of tea band, which seriously has a negative influence. This paper analyses the main problems of export tea packaging and puts forward corresponding countermeasures, aiming at solving the disadvantages of export tea packaging.

\section{Introduction}

With the rapid development of China's economy, China's tea export volume has also increased year by year. From January to December 2017, China's tea export volume was 355258 tons, an increase of 8.1\%, and from January to December 2017, China's tea export volume was 160,995,000 dollars, which is an increase of 8.4\%. China's tea exports from 2012 to 2017 are shown in figure 1 below.

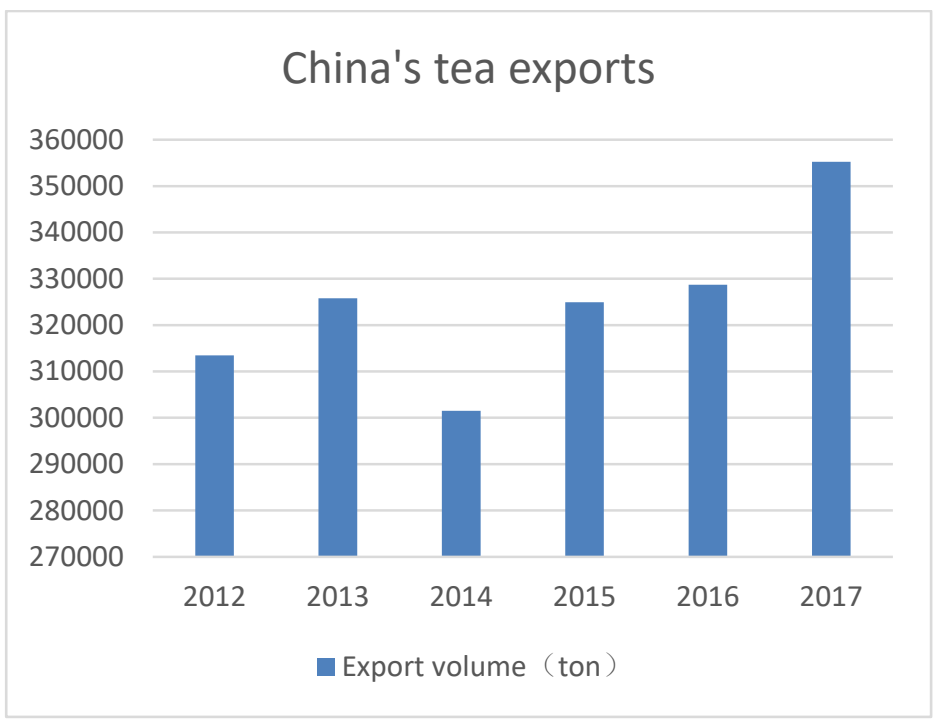

Figure 1 China's tea exports from 2012 to 2017 
Tea packaging is the most direct way for consumers to understand commodities. Packaging provides various valuable information. Translating Chinese into English on tea packaging in China will help consumers in other countries to understand the characteristics of tea ${ }^{[1]}$. It can effectively convey information, enhance the image of tea enterprises in China, and help tea enterprises in China move to the international market is of great help. However, at present, there is no effective management of tea export packaging in China. There are many kinds of problems in tea export packaging, among which translation errors are one of the common problems, which have a great negative impact on tea export in China, and even cause international disputes and unnecessary losses to tea enterprises in China. Therefore, in this context, we can fundamentally solve the problems of tea export packaging only by thoroughly analyzing the problems and Countermeasures of English translation on tea export packaging. ${ }^{[2]}$

\section{Problems in English Translation of Tea Export Packaging}

\subsection{Mechanical Translation of English}

In tea export packaging, the most common problems are mechanized literal translation and dead translation. Because some translators do not have a thorough knowledge of tea culture beforehand, coupled with their low degree of specialization, they often make this kind of mistakes in translation. This kind of translation is not only unfavorable to foreigners' understanding, but also makes tea culture look vulgar. For example, in the translation of Dragonwell green tea, some translators use Dragonwell green tea directly, instead of showing its characteristics, they depress its cultural charm.We can see it in the Figure 2 below.In fact, in the English translation of tea names, we usually use literal translation methods. For example, we translate green tea directly into "green tea", but this does not mean that all tea names can be generalized. If the translator adopts the translation method of swallowing jujubes and fails to pay attention to the study of its meaning, then the correct message can not be conveyed. Although it is not a big problem to adopt one-to-one correspondence in translation, the name "Longjing Tea" can also be understood by most foreigners, but it lacks the aesthetic sense of translation. According to the statistics of Google search engine, "Dragonwell green tea" corresponds to more pages than "Longjing Tea", although the former is relatively more complex, but it fully demonstrates the characteristics of the Chinese nation, so that the characteristics of culture are appearing, and more foreigners can establish the impression of tea culture, so that they can remember the band of Dragonwell green tea. ${ }^{[3]}$

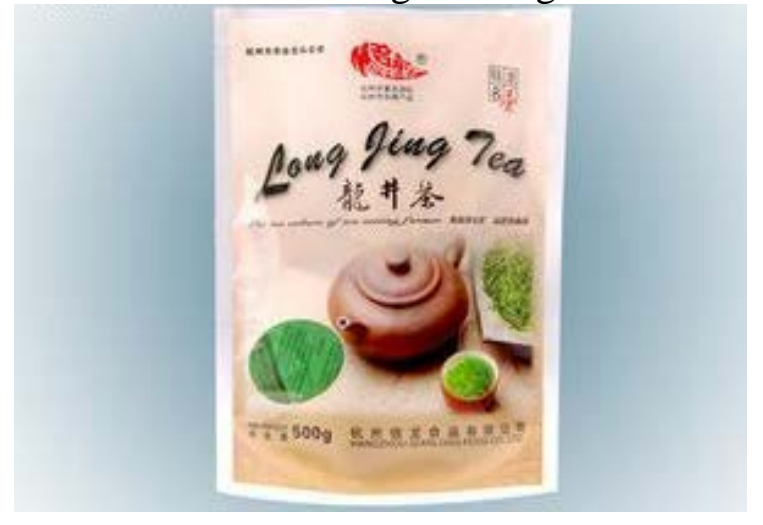

Figure 2 the mechanical translation of Dragonwell green tea

\subsection{Syntax error of English}

As a kind of food, the accuracy of tea language is more important. In the process of translation 
into English, it must meet the requirements of English grammar, so as to be understood by people. However, due to the great differences in grammar between Chinese and English, many consumers do not understand the information after seeing the tea packaging, which will have a negative impact on the image of the enterprise brand. For example, due to the limitation of tea preservation conditions, many tea leaves need to be sealed and preserved in closed places.Tea enterprises will adopt such a narrative way as "Please put it in a cool place to seal save", but according to the composition of English grammar, "to"must be followed by the original verb, so the following word sealing is obviously a grammatical error, although this more obvious grammatical error can be guessed by foreign consumers, but people will have doubts about the quality of the goods and the quality of the goods, the purchase interest will be greatly reduced, and the export of this kind of tea will also have a subtle negative impact. ${ }^{[4]}$

\subsection{Neglect of the Culture of Exporting Countries}

As we all know, the reason why there are so many differences among countries in the world lies in cultural differences, besides the uneven distribution of interests. Every nation has its own cultural pattern, and these cultural contents are formed in a certain historical environment, so it is difficult to achieve synchronization for a while. However, in reality, many translators do not pay attention to these cultural differences, let alone take into account the cultural characteristics and taboos of the exporting countries. For example, in China, yellow represents noble elegance and is a symbol of authority; In France, yellow represents infidelity and is a very eye-catching color, therefore, in the translation of tea color, we should try our best to avoid the emergence of light yellow, light yellow and other words, but at this point, many tea translations have not done enough.

\section{English Translation of Tea Export Packaging}

\subsection{Increasing Attention to the Translation of Tea Export Packaging}

Facts have proved that translation software not only fails to provide us with accurate translation, but also widens the distance between us and foreign consumers. Therefore, in the translation of tea export packaging, we should first establish a very serious attitude, and strengthen the importance of it. KFC and McDonald's have a huge market in China and are loved by countless teenagers because they have made a very deep study of Chinese taste, habits, style and Chinese cultural characteristics. In fact, their tables and chairs are based on a lot of data analysis, according to most of them. Chinese people are tailored for their height. Therefore, in Chinese traditional festivals, the packaging of KFC hamburgers will often become a very typical "Chinese style", and we will be attracted by KFC holiday packages, but abandon the traditional festival food of our Chinese nation. Therefore, if we want to open up the foreign tea market, we must start from the culture of the exporting country and pay more attention to the English translation of tea export. After the preliminary packaging design shaping, we should submit the design to the professional people for examination and confirmation. Once problems are found, we should modify it immediately to avoid grammatical error.

\subsection{Improving the Professional Level of Translators}

The fundamental reason why tea export packaging is so wrong is that the quality of translators is not high. If the level of specialization of translators is enough, then the mechanical translation method will probably not be used, so that all kinds of tea translation will not fall into a very embarrassing situation. Therefore, in view of this problem, tea enterprises must fundamentally 
improve the quality of professionals. Firstly, by means of training, translators can learn comprehensively and systematically about the tea market at home and abroad and the problems of English translation itself, so that they can have a good translation foundation. Secondly, enterprises can adopt regular cooperation with professional translation teams to find targeted solutions to difficult problems. In continuous communication, the quality of translators within enterprises can also be improved accordingly. Finally, enterprises should formulate a reasonable reward and punishment policy, reward the outstanding translators, and punish the wrong translators, so as to enhance the translators'sense of responsibility and mission. Only in this way can the professional quality of translators in enterprises be effectively improved, and there will be fewer and fewer mistakes in tea export packaging. ${ }^{[4]}$.

\subsection{Deeply Understanding the Cultural Characteristics of Exporting Countries}

In-depth understanding of the cultural characteristics of exporting countries is not only the needs of the market, but also to meet the psychological needs of consumers. The most important reason why a brand can arouse strong repercussions and endure for a long time is that it meets the psychological needs of consumers to some extent, besides its products deeply rooted in the hearts of the people. The psychological needs of consumers are determined by the big cultural background. Therefore, in the English translation of tea export packaging, we must have a thorough understanding of the cultural characteristics of the exporting countries. First of all, we should increase our understanding of the cultural background, customs and habits of exporting countries through Internet and books, and design the trend of tea packaging according to local cultural characteristics. $^{[5]}$ During this period, we should also pay attention not to touch sensitive cultural corners and edges. Secondly, even if we feel that the design of tea export packaging has been perfect enough, we should invite professional insiders to comment on it. Only by confirming the packaging repeatedly, can we ensure that the translation of tea export packaging is on the basis of maintaining the traditional cultural characteristics and attracting consumers sufficiently.

\section{Conclusions}

With the widespread use of English in the world, the English translation of tea export packaging has become the main language of cultural diffusion of tea culture. We should not neglect the English translation of tea packaging. On the contrary, we should use the wave of cultural dissemination to disseminate our tea culture and continuously develop our national culture. So that our tea culture can win the trust of foreign consumers.

\section{Acknowledgement}

"Practical Research on the Mixed Teaching Mode Based on Cloud Classroom in Higher Vocational Education” funded by Guangdong Higher Vocational and Technical Education Research Association in 2018 (Project No. GDGZ18Y046); "The Cultural Research on the Dynamic Interpretation of the Chinese Translation of Bible” funded by National Social Science Fund in 2016 (Project No. 16BYY027).

\section{References}

[1] Hu Xuekun.. Problems and Countermeasures of English Translation on Tea Export Packaging [J]. Tea in Fujian, 2017, 39(08):275-276.

[2] Wang Li. A Study on the Improving Strategies of English Translation of Export Tea Packaging [J]. Tea in Fujian, 2017, 39(08):130-131. 
[3] Wang Dongmei. A Skopos-based Study on English Translation of Tea Packaging in China [J]. Tea in Fujian, 2017, 39(03):121-122.

[4] Liu Jiangyan.. Application and Exploration of the Art of English Translation of Tea Packaging [J]. Tea in Fujian, 2017, 39(01):166-167.

[5] Liu Hongyan. Problems in English Translation of Tea Packaging [J]. Tea in Fujian, 2016, 38(07):172-173. 